\title{
X-ray analysis of 2-aniline benzo(2,3-b) cyclopentane-1,3-dione
}

\author{
RAJNIKANT*, DINESH, MOUSMI, M B DESHMUKH ${ }^{\dagger}$ and ANSHU SAWHNEY \\ Post-Graduate Department of Physics, University of Jammu, Jammu Tawi 180 006, India \\ ${ }^{\dagger}$ Department of Chemistry, Shivaji University, Kolhapur 416 004, India
}

MS received 17 February 2004; revised 26 April 2004

\begin{abstract}
The molecular and crystal structure of 2-aniline benzo(2,3-b) cyclopentane-1,3-dione has been determined by $\mathrm{X}$-ray crystallographic techniques. This compound crystallizes in the orthorhombic space group $P 22_{1} 2_{1}$ with unit cell parameters: $a=5.467(1), b=10 \cdot 657(3), c=19 \cdot 602(6) \AA ; V=1142 \cdot 01(5) \AA^{3}, Z=4$. The crystal structure has been resolved up to an $R$-factor 0.050 for 1129 reflections. All the three rings in the structure are planar. However, the dihedral angle between the phenyl ring and the moiety comprising of a five-membered and six-membered ring is $92.4^{\circ}$. The oxygen atom 01 acts as a trifurcated acceptor and is involved in the formation of three intermolecular interactions.
\end{abstract}

Keywords. Crystal structure; molecular interactions; X-ray diffraction; X-ray diffractometer; trifurcated acceptor.

\section{Introduction}

Alkaloids are used for the treatment of asthma, cough, tuberculosis, etc (Thappa et al 1996). They are also widely being abused as a recreational drug. It causes a variety of pharmacological effects on the central nervous system. The well known example is that of cocaine which when inhaled results in increased heart rate and blood pressure (Byke and Vandyke 1997). Carpaine is another such substance which is reported to be a kind of heart poison and it lowers the pulse frequency and depresses the central nervous system (Joshi et al 1996; Rajnikant et al 1998).

As a part of our on-going investigations on the preparation of X-ray diffraction quality single crystals and determination of some nitrogen containing molecules (Rajnikant et al 2002, 2003), the title compound has been investigated which shows antibacterial activity against a number of test organisms (Nedev et al 1989) and has been synthesized by heating $\mathrm{N}$-phenyl phthalahydrazide with ethyl chloroformate in acetone in presence of $\mathrm{K}_{2} \mathrm{CO}_{3}$. The chemical structure as shown in figure 1 has been assigned on the basis of IR, UV, NMR and mass spectral data (Deshmukh 2002).

\section{Experimental}

Three-dimensional intensity data of transparent rectangular plate shaped single crystal of 2-aniline benzo(2,3-b) cyclopentane-1,3-dione were collected on an Enraf-Nonius

\footnotetext{
*Author for correspondence
}

CAD-4 diffractometer. $\omega / 2 \theta$ scan mode was employed for data collection by using MoK $\alpha$ radiation $(\lambda=0.71069 \AA)$. The cell parameters were refined from accurately determined 25 reflections in the range of $8.21<\theta<13.45^{\circ}$. The cell measurement was carried out at room temperature, 293(2) K and CAD-4 programs were used for the refinement of unit cell parameters. A total of 1431 reflections were recorded in the $\theta$ range, $2.08<\theta<24.98^{\circ}$. Of the total number of reflections, 1309 were found unique (index range: $-2 \leq \mathrm{h} \leq 6,-5 \leq \mathrm{k} \leq 12,-11 \leq 1 \leq 23)$ and 1129 reflections were treated as observed $\left[F_{0}>4 \sigma\left(F_{0}\right)\right]$. Two standard reflections, $(\overline{1} \overline{1} \overline{9})(\overline{1} \overline{2} \overline{6})$, measured after every 100 reflections showed no significant variation in the intensity data which means that the crystal remained stable during exposure to X-rays. The reflection data were corrected for Lorentz and polarization effects. Absorption and extinction corrections were not applied.

The structure was elucidated by direct methods using SHELXS86 program (Sheldrick 1986). All non-hydrogen atoms of the molecule were located from the $E$-map. The $R$-factor was based on $E$-values, $R_{E}=0 \cdot 183$. Full-matrix

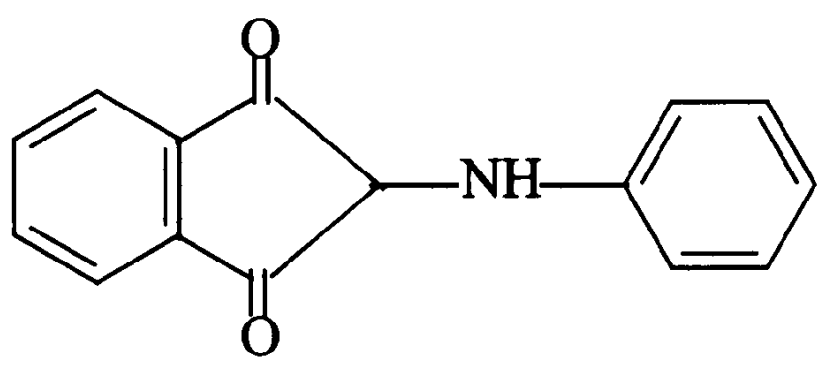

Figure 1. The chemical structure of the molecule. 
least-squares refinement of the structure was carried out by using SHELXL93 program (Sheldrick 1993). The positional and thermal parameters of non-hydrogen atoms were refined isotropically. All hydrogen atoms were fixed stereochemically. Further refinement with anisotropic thermal parameters resulted into a final value of the reliability in$\operatorname{dex}, R=0 \cdot 050$. The maximum and minimum values for the residual electron density were 0.36 and $-0.48 \mathrm{e}^{-3}$, respectively. Atomic scattering factors were obtained from International tables for Crystallography (1992, Vol. C tables $4 \cdot 2 \cdot 6 \cdot 8$ and $6 \cdot 1 \cdot 1 \cdot 4)$. The crystallographic data are listed in table 1 .

\section{Results and discussion}

The final atomic positions and equivalent isotropic displacement parameters for all the non-hydrogen atoms are listed in table 2. Bond lengths and bond angles for nonhydrogen atoms are given in table 3. A general view of the molecule indicating atomic numbering scheme (thermal ellipsoid drawn at $50 \%$ probability) is shown in figure 2 (Farrugia 1997). The geometrical calculations were performed using PARST program (Nardelli 1995).

The bond distances within the aromatic nucleus of the phenyl rings are in agreement with some related structures (Hunter et al 1985; Johnson et al 1989; Selladurai et al 1996). The $\mathrm{C} 1=\mathrm{O} 1$ and $\mathrm{C} 3=\mathrm{O} 2$ bonds have distances which depict their double bond character. The C2-N1 and $\mathrm{N} 1-\mathrm{C} 10$ bonds linking the phenyl ring with rest of the molecule have distances slightly smaller and greater than the standard value of $1.41 \AA$. This phenomenon is

Table 1. Crystal data and structure refinement details.

\begin{tabular}{ll}
\hline Crystal description & Pale yellow rectangular plates \\
Empirical formula & $\mathrm{C}_{15} \mathrm{H}_{11} \mathrm{NO}_{2}$ \\
Formula weight & $236 \cdot 24$ \\
Temperature & $293(2) \mathrm{K}$ \\
$\begin{array}{l}\text { Crystal system, space } \\
\text { group }\end{array}$ & Orthorhombic, $P 2_{1} 2_{1} 2_{1}$ \\
Unit cell dimensions & $a=5 \cdot 467(10), b=10 \cdot 657(3)$, \\
& $c=19 \cdot 602(6) \AA$ \\
$Z$, volume, calculated den- & $4,1142 \cdot 01(5) \AA^{3}, 1 \cdot 374 \mathrm{Mg} / \mathrm{m}^{3}$ \\
sity & \\
Absorption coefficient & $0 \cdot 092 \mathrm{~mm}^{-1}$ \\
$F(000)$ & 492 \\
Crystal size & $0 \cdot 30 \times 0 \cdot 3 \times 0 \cdot 2 \mathrm{~mm}$ \\
Radiation, wavelength $(\lambda)$ & $\mathrm{MoK} \alpha, 0 \cdot 71069 \AA$ \\
$\theta$ range for data collection & $2 \cdot 08$ to $24 \cdot 98^{\circ}$ \\
Index ranges & $-2 \leq h \leq 6,-5 \leq k \leq 12,-11 \leq l \leq 23$ \\
No. of reflections col- & $1431 / 1309[R($ int $)=0 \cdot 0058]$ \\
lected/unique & \\
Largest diff. peak and hole & $0 \cdot 36<\Delta \rho<-0 \cdot 48$ e $\AA^{-3}$ \\
Refinement method & Full-matrix least-square on $F^{2}$ \\
Data/restraints/parameters & $1309 / 0 / 164$ \\
Final $R$ indices $\left[F_{0}>4 \sigma F_{0}\right]$ & $R_{1}=0 \cdot 050, w R_{2}=0 \cdot 166$ \\
$R$ indices (all data) & $R_{1}=0 \cdot 062$ \\
Goodness of fit & $1 \cdot 337$ \\
\hline &
\end{tabular}

quite prevalent in the molecules where nitrogen is abridged between two rings (Meurisse et al 1992). The exocyclic bond angles at the ring junction i.e. at $\mathrm{C} 8$ and $\mathrm{C} 9$, are $130 \cdot 6(4)^{\circ}$ and $130 \cdot 3(4)^{\circ}$, respectively. The large value of the bond angle could be attributed to the stretching of the molecule along its mean molecular axis. The endocyclic bond angles at $\mathrm{C} 2$ and $\mathrm{C} 10$ have values slightly greater and smaller than the standard values.

Table 2. Atomic coordinates and equivalent isotropic temperature factors $\left(\AA^{2}\right)$ with e.s.d.'s in parentheses, for the non-hydrogen atoms.

\begin{tabular}{|c|c|c|c|c|}
\hline Atom & $X$ & $Y$ & $Z$ & $U_{\text {eq. }}{ }^{*}$ \\
\hline N1 & $0.4449(7)$ & $0.0219(3)$ & $0.9546(2)$ & $0 \cdot 0647(1)$ \\
\hline $\mathrm{O} 1$ & $0 \cdot 6168(6)$ & $0 \cdot 1164(3)$ & $0.8285(2)$ & $0.0848(1)$ \\
\hline $\mathrm{O} 2$ & $-0.0033(5)$ & $0 \cdot 1526(3)$ & $0 \cdot 9841(1)$ & $0.0684(1)$ \\
\hline $\mathrm{C} 1$ & $0.4314(8)$ & $0 \cdot 1588(4)$ & $0 \cdot 8546(2)$ & $0.0630(1)$ \\
\hline $\mathrm{C} 2$ & $0 \cdot 3660(6)$ & $0 \cdot 1157(3)$ & $0.9166(2)$ & $0 \cdot 0414(1)$ \\
\hline C3 & $0 \cdot 1218(8)$ & $0 \cdot 1766(4)$ & $0 \cdot 9348(2)$ & $0 \cdot 0563(1)$ \\
\hline $\mathrm{C} 4$ & $-0 \cdot 0953(8)$ & $0 \cdot 3622(4)$ & $0 \cdot 8743(2)$ & $0 \cdot 0608(1)$ \\
\hline $\mathrm{C} 5$ & $-0.0876(9)$ & $0.4391(4)$ & $0 \cdot 8174(2)$ & $0.0683(1)$ \\
\hline C6 & 0.0964(10) & $0.4269(4)$ & $0.7686(2)$ & $0.0724(2)$ \\
\hline C7 & $0.2757(9)$ & $0 \cdot 3365(4)$ & $0.7756(2)$ & $0.0709(2)$ \\
\hline $\mathrm{C} 8$ & $0 \cdot 2674(8)$ & $0 \cdot 2598(4)$ & $0.8326(2)$ & $0.0589(1)$ \\
\hline C9 & $0 \cdot 0836(8)$ & $0 \cdot 0105(3)$ & $0.8809(2)$ & $0.0532(1)$ \\
\hline C10 & $0.4337(7)$ & $-0 \cdot 1013(4)$ & $0 \cdot 9268(2)$ & $0 \cdot 0540(1)$ \\
\hline C11 & $0 \cdot 6141(8)$ & $-0 \cdot 1872(4)$ & $0 \cdot 9448(2)$ & $0.0647(2)$ \\
\hline C12 & $0 \cdot 8970(9)$ & $-0 \cdot 3095(4)$ & $0 \cdot 9222(2)$ & $0 \cdot 0705(2)$ \\
\hline C13 & $0 \cdot 4062(9)$ & $-0 \cdot 3474(4)$ & $0 \cdot 8821(2)$ & $0.0690(2)$ \\
\hline C14 & $0 \cdot 2303(8)$ & $-0 \cdot 2619(4)$ & $0.8639(2)$ & $0.0686(2)$ \\
\hline C15 & $0 \cdot 2428(8)$ & $-0.1391(4)$ & $0 \cdot 8866(2)$ & $0.0611(1)$ \\
\hline
\end{tabular}

$U_{\mathrm{eq}}^{*}=(1 / 3) \sum_{i} \sum_{j} U_{i j} a_{i}^{*} a_{j}^{*}\left(a_{i} \cdot a_{j}\right)$

Table 3. Bond distances $(\AA)$ and bond angles $\left({ }^{\circ}\right)$ for non-hydrogen atoms (e.s.d.'s are given in parentheses).

\begin{tabular}{llll}
\hline N1-C2 & $1 \cdot 380(5)$ & N1-C10 & $1 \cdot 423(5)$ \\
C1-C2 & $1 \cdot 399(6)$ & C1-C8 & $1 \cdot 465(6)$ \\
C1-O1 & $1 \cdot 221(6)$ & C2-C3 & $1 \cdot 388(5)$ \\
C3-C9 & $1 \cdot 489(6)$ & C3-O2 & $1 \cdot 211(5)$ \\
C4-C5 & $1 \cdot 385(6)$ & C4-C9 & $1 \cdot 369(6)$ \\
C5-C6 & $1 \cdot 394(7)$ & C6-C7 & $1 \cdot 381(7)$ \\
C7-C8 & $1 \cdot 385(6)$ & C8-C9 & $1 \cdot 388(6)$ \\
C10-C11 & $1 \cdot 391(6)$ & C10-C15 & $1 \cdot 368(6)$ \\
C11-C12 & $1 \cdot 380(6)$ & C12-C13 & $1 \cdot 367(6)$ \\
C13-C14 & $1 \cdot 372(6)$ & C14-C15 & $1 \cdot 384(6)$ \\
C2-N1-C10 & $116 \cdot 3(3)$ & C8-C1-O1 & $131 \cdot 0(4)$ \\
C2-C1-O1 & $123 \cdot 3(4)$ & C2-C1-C8 & $105 \cdot 7(3)$ \\
N1-C2-C1 & $123 \cdot 2(4)$ & C1-C2-C3 & $112 \cdot 5(3)$ \\
N1-C2-C3 & $124 \cdot 3(3)$ & C2-C3-O2 & $125 \cdot 7(4)$ \\
C2-C3-C9 & $105 \cdot 0(3)$ & C9-C3-O2 & $129 \cdot 3(4)$ \\
C5-C4-C9 & $117 \cdot 7(4)$ & C4-C5-C6 & $121 \cdot 3(4)$ \\
C5-C6-C7 & $121 \cdot 2(5)$ & C6-C7-C8 & $117 \cdot 9(4)$ \\
C1-C8-C7 & $130 \cdot 6(4)$ & C7-C8-C9 & $120 \cdot 9(4)$ \\
C1-C8-C9 & $108 \cdot 5(4)$ & C4-C9-C8 & $121 \cdot 6(4)$ \\
C3-C9-C8 & $108 \cdot 2(3)$ & C3-C9-C4 & $130 \cdot 3(4)$ \\
N1-C10-C15 & $121 \cdot 7(4)$ & N1-C10-C11 & $118 \cdot 7(4)$ \\
C11-C10-C15 & $119 \cdot 5(4)$ & C10-C11-C12 & $119 \cdot 5(4)$ \\
C11-C12-C13 & $121 \cdot 0(4)$ & C12-C13-C14 & $119 \cdot 2(4)$ \\
C13-C14-C15 & $120 \cdot 7(4)$ & C10-C15-C14 & $120 \cdot 1(4)$ \\
\hline
\end{tabular}




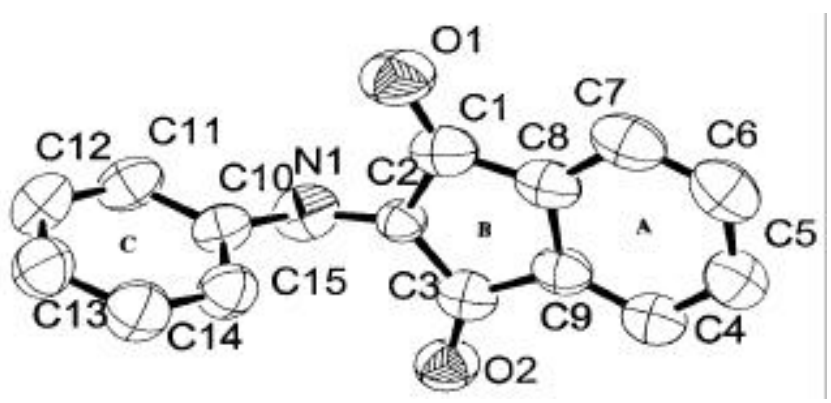

Figure 2. General view of the molecule indicating atomic numbering scheme.

Ring A containing atoms C4-C9 define a plane in which maximum deviation has been found for atom C6[-0.003(5) $\AA$ ]. The atoms C1 and C3 which have not been included in the calculation of the least square plane are found to have a deviation of $-0.023(4)$ and $0.022(4) \AA$, respectively. This indicates that the atom $\mathrm{C} 1$ is lying below the plane and C3 is lying above the plane of ring A. The average value of torsion angles in this ring is $0 \cdot 37(6)^{\circ}$. In ring $\mathrm{B}$, maximum deviation has been obtained for atom C3[0.022(4) A] . The atoms O1, O2 and N1 which have not been included in the least squares plane calculation have a deviation of 0.009(3), 0.081(4) and -0.051(4), respectively. This shows that $\mathrm{O} 1$ and $\mathrm{O} 2$ atoms are lying above the plane and N1 is lying below the plane comprising of ring $\mathrm{B}$ atoms. The average value of torsion angles in this ring is $2 \cdot 2(5)^{\circ}$. The ring $\mathrm{C}$ with atoms $\mathrm{C} 10, \mathrm{C} 11, \mathrm{C} 12, \mathrm{C} 13$, $\mathrm{C} 14$, and $\mathrm{C} 15$ define a plane from which the largest deviation is observed in case of atom C14 (0.006(4) $\AA$ ). The atom $\mathrm{N} 1$ which has not been included in the calculation of the least square plane is found to be deviated below the plane of ring $\mathrm{C}$ by $-0 \cdot 086(4) \AA$. The average value of torsion angles in this ring is $0.57(6)^{\circ}$.

The torsion angle C3-C2-N1-C10 is $109 \cdot 2(4)^{\circ}$, a rotation of nitrogen containing phenyl group that effectively takes it out of conjugation with the rest of the molecule. The dihedral angle between the plane consisting of atoms $\mathrm{C} 1-\mathrm{C} 9$ and the phenyl ring $\mathrm{C}$ is $92.40(1)^{\circ}$ which clearly indicates that the phenyl ring is placed at almost right angle to the remaining molecule. There exists the following three intermolecular interactions (Jeffrey and Lewis 1978; Taylor and Kennard 1983):

$$
\begin{aligned}
& \text { D-H...A } \quad \text { H...A }(\AA) \text { D...A }(\AA) \text { D-H...A }\left(^{\circ}\right) \\
& \begin{array}{llll}
\mathrm{C} 5-\mathrm{H} 5 \ldots \mathrm{O} 1^{(\mathrm{i})} & 1 \cdot 38(1) & 1 \cdot 91(1) & 110 \cdot 3(5) \\
\mathrm{C}-\mathrm{H} 6 \ldots \mathrm{OO} 1^{(\mathrm{ii})} & 2 \cdot 43(1) & 3 \cdot 19(1) & 138 \cdot 9(4) \\
\mathrm{C} 14-\mathrm{H} 14 \ldots \mathrm{O} 1^{(\mathrm{iii})} & 1 \cdot 59(1) & 2 \cdot 40(1) & 144 \cdot 0(5)
\end{array}
\end{aligned}
$$

Equivalent position: (i) $-x+1 / 2,+y+1 / 2+1,+\mathrm{z}$ (ii) $-x+$ $1 / 2,+y+1 / 2,-z+1 / 2+1$ (iii) $-x+1 / 2,+y-1 / 2,+z$

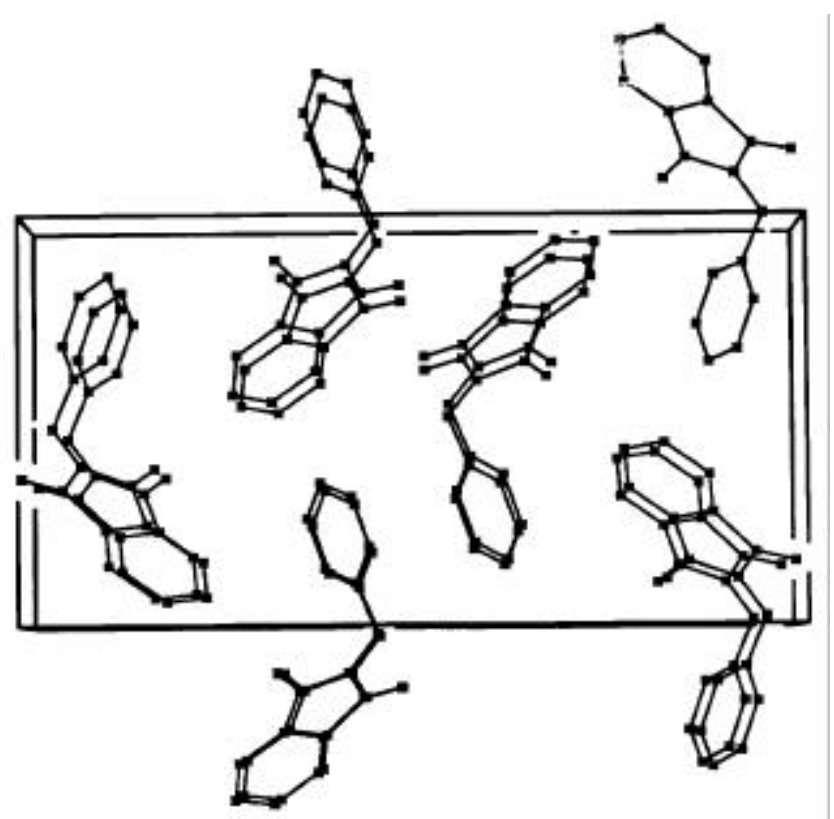

Figure 3. Unit cell molecular packing down a-axis.

The analyses of these interactions clearly indicate that the oxygen atom $\mathrm{O} 1$ acts as a trifurcated acceptor (Desiraju and Steiner 1999). Down the $a$-axis (figure 3), the molecule appears to be stacked one above another in the same orientation. The crystal structure is also stabilized by van der Waals interaction.

\section{Acknowledgements}

One of the authors (Rajnikant) is thankful to the University Grants Commission, New Delhi, for financial support under its DRS Research Project no: F.530/3/DRS/2001(SAP-I).

\section{References}

Byke R and Vandyke C 1997 Cocaine (eds) R C Peterson and R C Stillman (Washington) p. 97

Deshmukh M B 2002 Private Communication, Shivaji University, Kolhapur, India

Desiraju G J and Steiner T 1999 The weak hydrogen bond (New York: IUCr)

Farrugia L J 1997 J. Appl. Cryst. 30565

Hunter D, Neilson D G and Weakley T J R 1985 J. Chem. Soc. Perkin Trans. 12709

Jeffrey G A and Lewis L 1978 Carbohydr. Res. 60178

Johnson A T, Keszler D A, Sakuma K and White J D 1989 Acta Crystallogr. C45 1114

Joshi B S, Newton M G, Lee D W, Barber A D and Pelletier S W 1996 Tetrahedron Asymmetry 725

Meurisse R L, Blaton N M, Peeters O M and De Ranter C J 1992 Acta Crystallogr. C48 508

Nardelli M 1995 J. Appl. Cryst. 28659 
Nedev K H, Minchev S and Noneva S 1989 Dokl Bolg. Akad. Nauk. 4231

Rajnikant, Gupta V K, Lal M, Rangari V D, Belsare D P, Soni B S and Varghese B 1998 Mol. Mater. 9131

Rajnikant, Dinesh, Mousmi, Deshmukh M B, Patil S S and Anshu Sawhney 2002 J. Chem. Crystallogr. [communicated]

Rajnikant, Gupta V K, Dinesh, Mousmi, Deshmukh M B, Salunke D K, Dhondage S R and Anshu Sawhney 2003 Asian J. Phys. 1293
Selladurai S, Subramanian K, Lakshmi S, Chen Y, Holt E J and Rao S N 1996 Acta Crystallogr. C52 94

Sheldrick G M 1986 SHELXS86 program for the solution of crystal structures (Germany: University of Gottingen)

Sheldrick G M 1993 SHELXS93 program for the refinement of crystal structures (Germany: University of Gottingen)

Taylor R and Kenard O 1983 Acta Crystallogr. B39 133

Thappa R K, Agarwal S G, Dhar K L, Gupta V K and Goswami K N 1996 Phytochemistry 421485 